\title{
Effects of sub-lethal teratogen exposure during larval development on egg laying and egg quality in adult
}

\section{Caenorhabditis elegans [version 1; peer review: 2 approved]}

\author{
Alexis Killeen, Caralina Marin de Evsikova \\ Department of Molecular Medicine, Morsani College of Medicine, University of South Florida, Tampa, USA
}

\author{
V1 First published: $28 \operatorname{Dec} 2016, \mathbf{5 : 2 9 2 5}$ \\ https://doi.org/10.12688/f1000research.8934.1 \\ Latest published: 28 Dec 2016, 5:2925 \\ https://doi.org/10.12688/f1000research.8934.1
}

\begin{abstract}
Background: Acute high dose exposure to teratogenic chemicals alters the proper development of an embryo leading to infertility, impaired fecundity, and few viable offspring. However, chronic exposure to subtoxic doses of teratogens during early development may also have long-term impacts on egg quality and embryo viability. Methods: To test the hypothesis that low dose exposure during early development can impact long-term reproductive health, Caenorhabditis elegans larvae were exposed to 10 teratogens during larval development, and subsequently were examined for the pattern of egg-laying and egg quality (hatched larvae and embryo viability) as gravid adults. After the exposure, adult gravid worms were transferred to untreated plates and the numbers of eggs laid were recorded every 3 hours, and the day following exposure the numbers of hatched larvae were counted. Results: While fecundity and fertility were typically impaired by teratogens, unexpectedly, many teratogens initially increased egglaying at the earliest interval compared to control but not at later intervals. However, egg quality, as assessed by embryo viability, remained the same because many of the eggs $(<50 \%)$ did not hatch. Conclusions: Chronic, low dose exposures to teratogens during early larval development have subtle, long-term effects on egg laying and egg quality.
\end{abstract}

\section{Keywords}

Arsenic , Benzo-a-pyrene, Biocides, Bisphenol A, Cadmium , Cigarette smoke, Combustion Pollutants, Diethylstilbestrol , Egg Laying , Egg Hatching , Egg Viability, Endocrine Disruptors, Fenthion , Nicotine , Tributyltin , Triclosan

\section{Open Peer Review}

Approval Status

1 2

version 1

28 Dec 2016

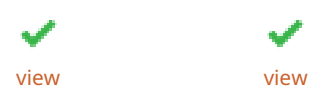

1. Keith T. Jones, University of Southampton,

Southampton, UK

2. Keith P. Choe, University of Florida,

Gainesville, USA

Any reports and responses or comments on the article can be found at the end of the article. 
Corresponding author: Caralina Marin de Evsikova (cmarinde@health.usf.edu)

Competing interests: The authors have no competing interests to disclose.

Grant information: C.elegans N2 ancestral strain and E. coli OP50 strain was provided by the CGC, which is funded by NIH Office of Research Infrastructure Programs (P40 OD010440).

Copyright: @ 2016 Killeen A and Marin de Evsikova C. This is an open access article distributed under the terms of the Creative Commons Attribution License, which permits unrestricted use, distribution, and reproduction in any medium, provided the original work is properly cited. Data associated with the article are available under the terms of the Creative Commons Zero "No rights reserved" data waiver (CCO 1.0 Public domain dedication).

How to cite this article: Killeen $A$ and Marin de Evsikova C. Effects of sub-lethal teratogen exposure during larval development on egg laying and egg quality in adult Caenorhabditis elegans [version 1; peer review: 2 approved] F1000Research 2016, 5:2925 https://doi.org/10.12688/f1000research.8934.1

First published: 28 Dec 2016, 5:2925 https://doi.org/10.12688/f1000research.8934.1 


\section{Introduction}

Teratogens are agents that negatively impact reproduction and embryonic development and include radiation, maternal infections, pharmaceuticals, and chemicals (Wilson, 1973). Numerous chemicals act as teratogens that adversely affect human health, with the time period of exposure as a critical factor determining teratogen susceptibility. For instance, maternal and prenatal teratogen exposure is associated with birth defects, spontaneous abortion, and stillbirth, and sometimes cancer in the reproductive tract of progeny (Reed et al., 2013; Sanders et al., 2014; Wigle et al., 2008). Previous studies demonstrated that acute, high-dose teratogen exposure causes reproductive decline, but the long-term ramifications of low dose teratogen exposure during early development later in life remain unknown (Allard \& Colaiácovo, 2010; Parodi et al., 2015). In this study, we used egg-laying, hatching, and offspring viability assays phenotyping screen throughout early development after exposing Caenorhabditis elegans to sub-lethal doses from in three classes of teratogens, including biocides, endocrine disruptors, and combustion pollutants, to detect impacts on reproductive phenotype in adults.

In addition, identification of the time frame, yielding the maximal egg-laying, after teratogen exposure, is critical for behavioral and developmental experiments requiring an aged-matched offspring population. The results of our study guide experimental procedures to obtain the requisite population size for subsequent experiments employing 3 hours egg-laying time window to achieve developmentally synchronous, aged-matched offspring population for subsequent experiments assessing long-term effects.

\section{Methods}

\section{Caenorhabditis elegans maintenance}

$\mathrm{N} 2$ ancestral Bristol strain of C. elegans (CGC, Minneapolis, MN, USA) were maintained on NGM lite plates (N1005, US Biologicals, Salem, MA, USA) with bacterial lawns at $25 \pm 0.5^{\circ} \mathrm{C}$ for all experiments. Bacterial lawns were grown on Petri dishes $(10,60,100 \mathrm{~mm}$ Corning, USA) overnight using 10, 20 or $60 \mu \mathrm{l}$ of $1 \mathrm{X}$ E. coli OP50 (CGC, Minneapolis, MN, USA; $1 \mathrm{X}=\mathrm{OD}_{600}=8.0 \times 10^{8}$ cells $/ \mathrm{mL}$ ).

\section{Chemicals}

Teratogens, except for cigarette smoke extract, were purchased from Sigma Aldrich (St. Louis, MO, USA): tributyltin-chloride
(0.1 $\mu \mathrm{M}$, T50202), cadmium-chloride $(0.5 \mu \mathrm{M}, \mathrm{C} 2554)$, benzo- $\alpha$ pyrene $(0.5 \mu \mathrm{M}, \mathrm{B} 1760)$, nicotine $(0.5 \mu \mathrm{M}, \mathrm{N}-3876)$, bisphenol-A (10 $\mu \mathrm{M}, 239658)$, diethylstilbestrol (10 $\mu \mathrm{M}, \mathrm{D} 4628)$, arsenic(III) oxide $(0.5 \mu \mathrm{M}, \mathrm{A} 1010)$, triclosan $(0.1 \mu \mathrm{M}$ PHR1338), fenthion $(0.1$, $1 \mu \mathrm{M}, 36552)$. Cigarette smoke extract $(0.1 \mu \mathrm{M})$ was purchased from Murty Pharmaceuticals (0.1 $\mu$ M, Lexington, KY, USA). Stock solutions of teratogens were made in DMSO or water, and final concentrations were adjusted to contain $0.01 \%$ DMSO (ACS grade, Fisher Scientific, USA). Sub-lethal doses were chosen based on preliminary studies (unpublished McIntyre, Killeen \& Marín de Evsikova).

\section{Experimental procedure}

The experimental design for all studies is depicted in Figure 1. A mixed population of worms was used to prepare a developmentally synchronized population at L1 larval stage (Stiernagle, 2006). All plates were coded to prevent experimenter bias. Larvae were transferred onto vehicle or teratogen exposure plates (with bacterial lawns) and cultivated for 48 hours at $25^{\circ} \mathrm{C}$ (Figure 1). Adult worms from each group were washed 3 times in M9 buffer and transferred into a well in the first row of a 24-well NGM plate. These worms were moved to an adjacent well every three hours for 12 hours. Laid eggs, and the following day, hatched embryos were counted. Embryo viability was determined as the ratio of hatched larvae to number of eggs. Experiments were repeated six times ( $\mathrm{n}=60$ worms/group, yielding $\mathrm{N}=660$ worms), albeit fenthion, which was repeated twice at $1 \mu \mathrm{M}(\mathrm{n}=20)$, and after unexpectedly curtailed egg-laying, the dose was decreased to $0.1 \mu \mathrm{M}(\mathrm{n}=40)$. Statistically significant differences were determined after outlier analysis using SPSS v. 23 software (IBM, USA) by ANOVA followed by post hoc or nonparametric $\left(\mathrm{X}^{2}\right.$ or Fisher's Exact Tests) for fecundity, fertility, eggs laid, hatched larvae, and embryo viability among all groups with significance set at $\mathrm{p}<0.05$.

\section{Results}

Fecundity and fertility, measures of reproductive fitness of the organism, were decreased after worms were exposed to the biocides, triclosan and fenthion, and combustion pollutant, benzo$\alpha$-pyrene (BAP; $\mathrm{X}^{2}=11.27,5.21$, and $83.1, \mathrm{p}<0.05$, respectively, Figure 2A \& B). Despite the overall detrimental effect on fecundity and fertility, the initial temporal pattern of egg laying

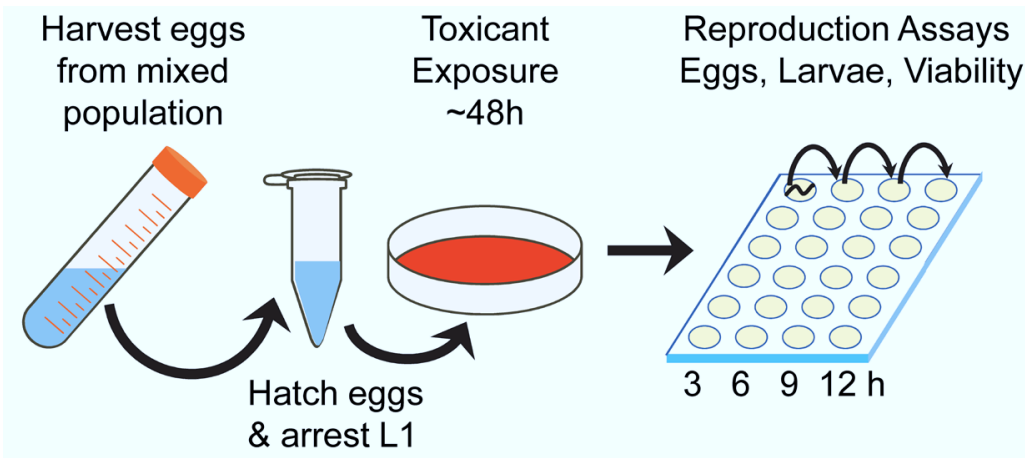

Figure 1. Study experimental design and procedure. An age-synchronized population of $C$. elegans L1 larvae was exposed to $10 \mathrm{known}$ teratogens at sub-lethal, micromolar concentrations for 48 hours. Gravid adult worms were transferred to pure NGM with bacterial lawns and the number of eggs laid was recorded every 3 hours up to 12 hours. Hatched larvae counted the following day. 
A

Fecundity

- Egg Layers (\%) $\square$ Non-Layers (\%)

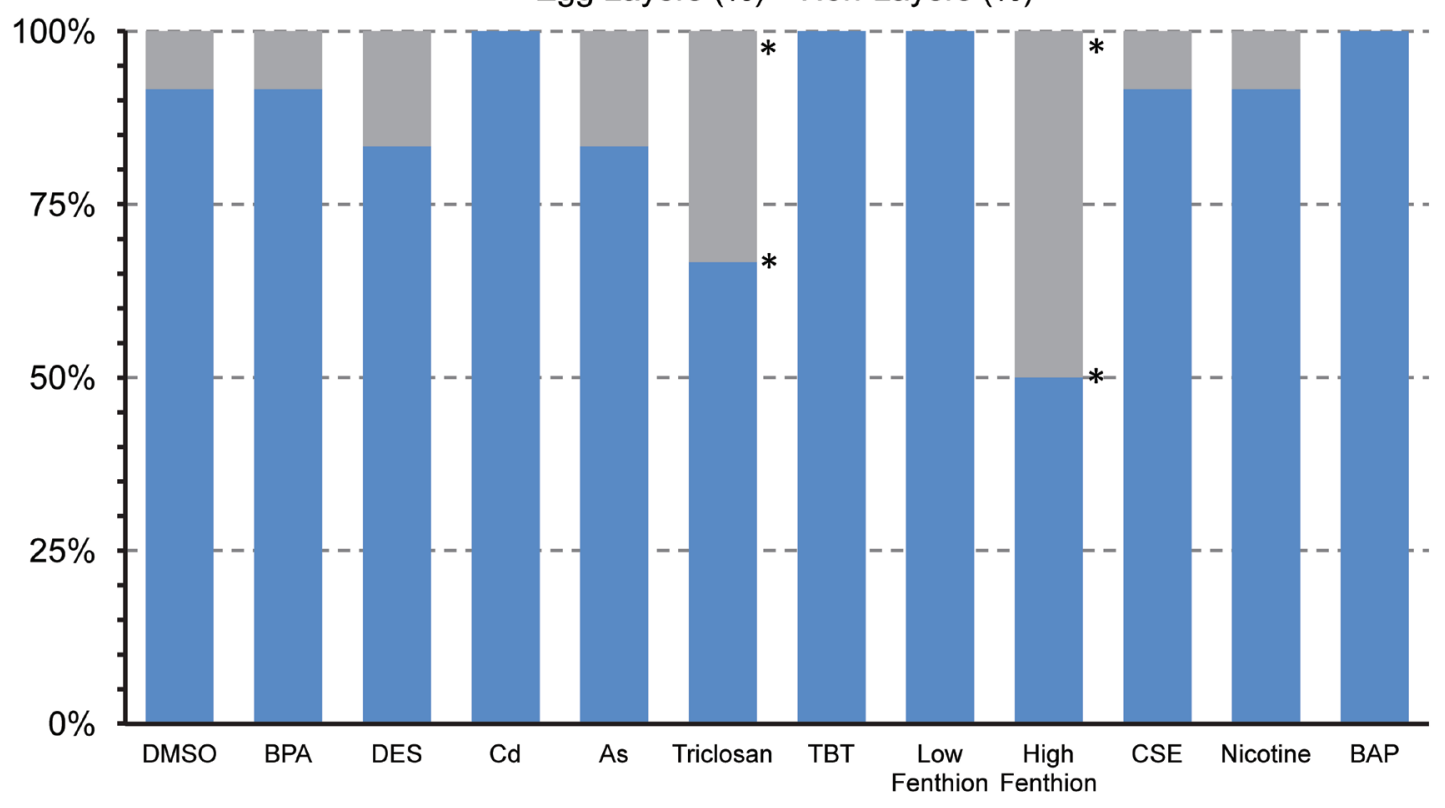

B

Fertility

- Viable Eggs (\%) $\quad$ Dead Eggs (\%)

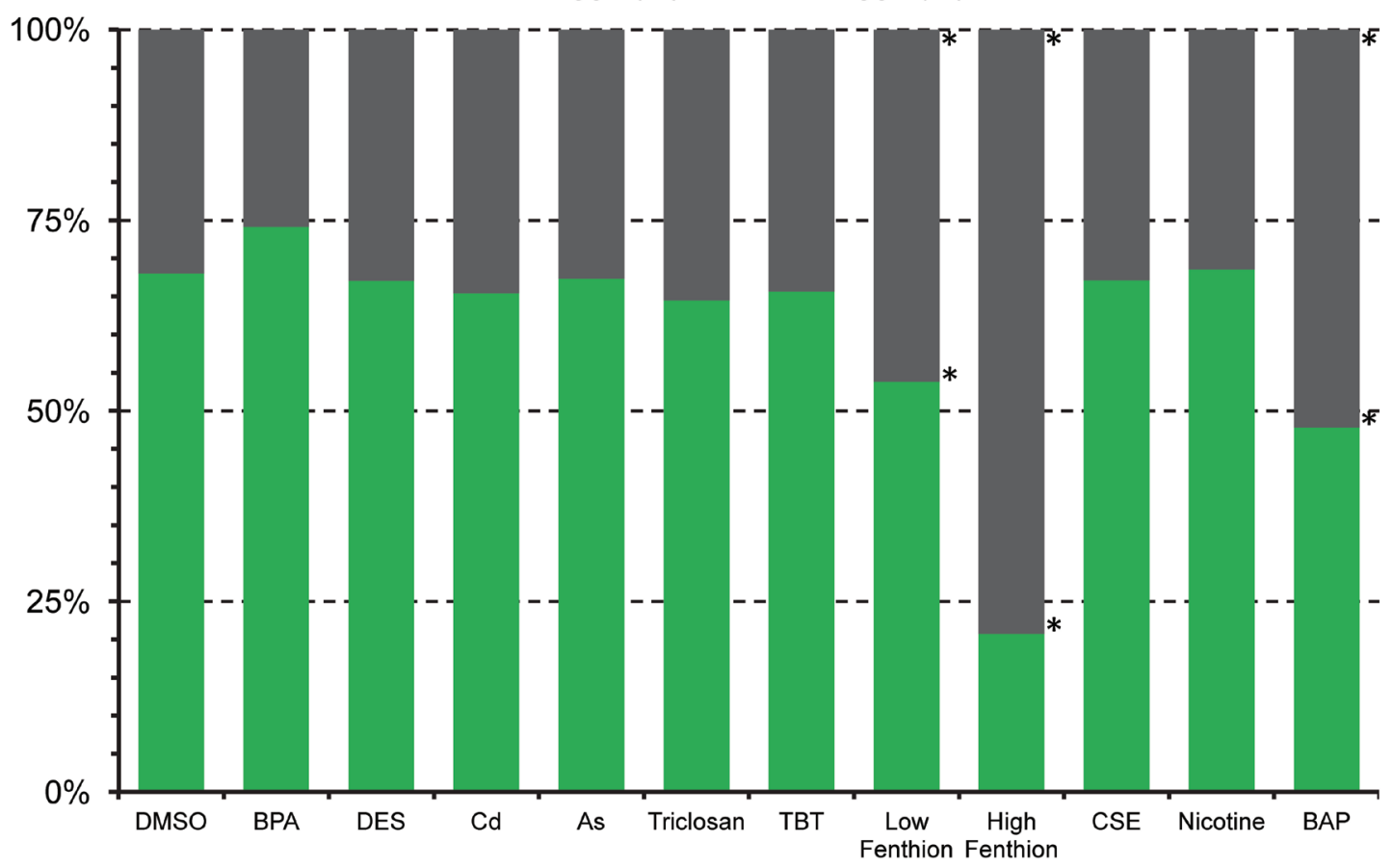

Figure 2. Effects of teratogens on fecundity $(\mathbf{A})$ and fertility (B). The overall percentage of worms that laid eggs shown as fecundity and the overall percentage of viable and dead eggs as a measure of fertility. Asterisks indicate $P<0.05$. 
was increased by some teratogens. The cumulative amount of eggs laid, irrespective of teratogen or vehicle, increased over time except for $1 \mu \mathrm{M}$ dose of fenthion (Figure 3A, $F(3,162)=119$, $\mathrm{p}<0.05)$. Furthermore, chronic larval exposure to some low dose teratogens, such as nicotine, cadmium, and tributyltin, increased egg laying and cumulatively produced more eggs than vehicle control (Figure 3A). Unexpectedly, many teratogens, except for arsenic and benzo- $\alpha$-pyrene, produced more eggs during the $0-3$ hours interval compared to vehicle (Figure 3B), although this interval had the overall lowest yield of eggs. While the greatest amount of egglaying occurred during the 9-12 hours compared to the $0-3$ hours interval, no differences in the amount of eggs laid were detected among the intervals at 3-6 hours, 6-9 hours, and 9-12 hours ( $p>0.05$ ). Hatched larvae, unlike eggs, did not increase at any interval after teratogen exposure (Figure 4B, $F(33,162)=1.051$ ) but total hatched larvae increased cumulatively by 12 hours $(F(3,162)=24.8$, $\mathrm{p}<0.05$ ). Despite these increases, egg quality did not improve after teratogen exposure as overall embryo viability was similar across groups and time points (Figure 5A $F(33,162)=1.015, P>.4$ ) with lowest viability at the first interval (Figure $5 \mathrm{~B}$ ) albeit not significant.

Dataset 1. Dataset of screening sub-lethal teratogens on egg laying, hatching and viability in adult $C$. elegans during larval development

http://dx.doi.org/10.5256/f1000research.8934.d124253

Data files contain raw data of the effect of teratogens on larva hatching, egg laying and viability in C. elegans. (Killeen \& Marín de Evsikova, 2016)
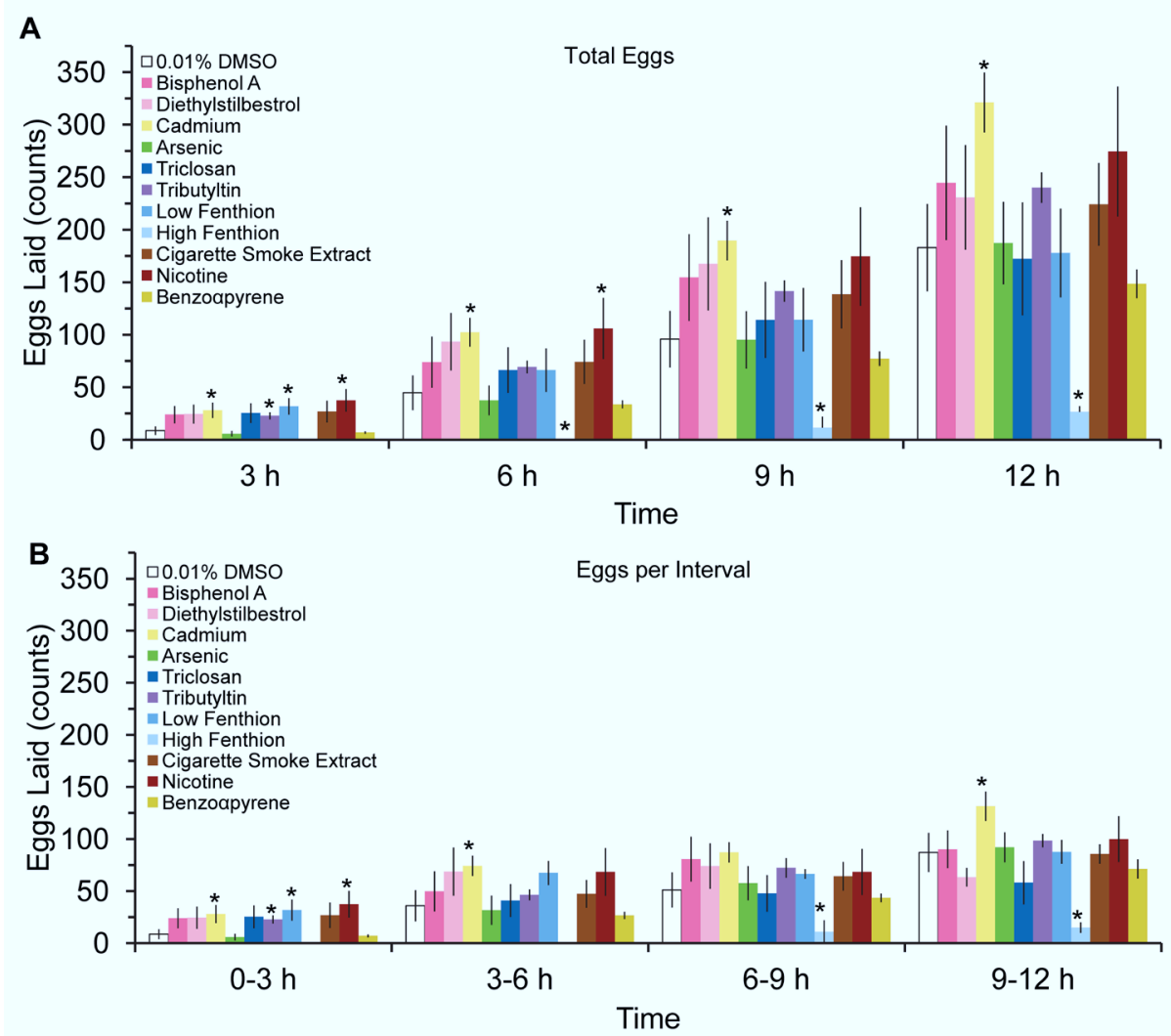

Figure 3. Effects of teratogens on egg-laying. Temporal pattern of $(\mathbf{A})$ cumulative eggs laid at 3, 6, 9 and 12 hours post-exposure, and (B) rate of eggs laying in 3 hours intervals (mean \pm sem). Asterisks indicate $P<0.05$. 

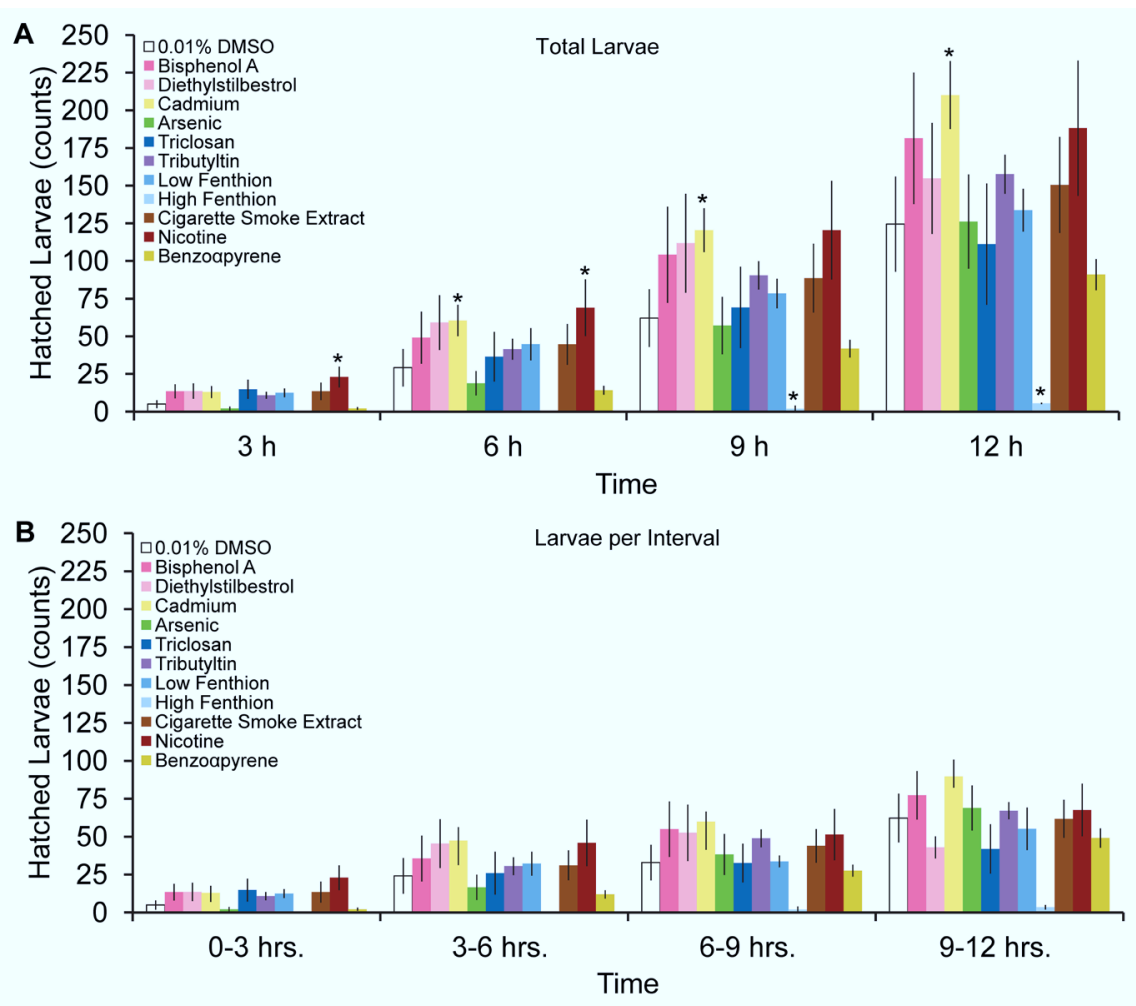

Figure 4. Effects of teratogens on hatched larvae. Temporal pattern of $(\mathbf{A})$ cumulative hatched larvae from eggs laid at 3, 6, 9 and 12 hours post-exposure to teratogens and (B) number of hatched larvae per teratogen group or control in 3 hours intervals (mean \pm sem). Asterisks indicate $P<0.05$.

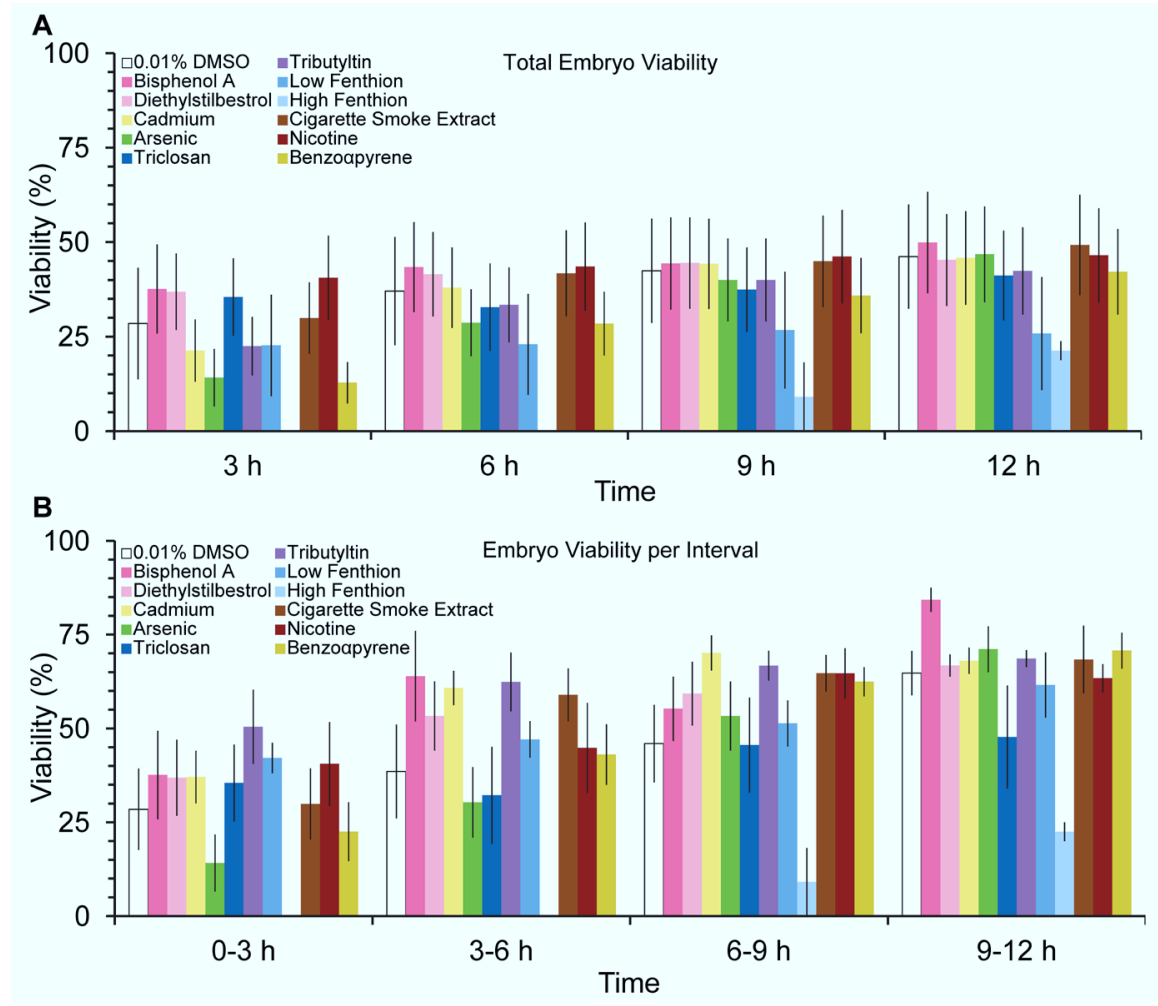

Figure 5. Effects of teratogens on embryo viability. Temporal pattern of (A) overall embryo viability at 3, 6, 9 and 12 hours post-exposure to teratogens and (B) embryo viability at 3 hours intervals. Embryo viability calculated as the ratio of hatched larvae/eggs laid $X 100 \%$ (mean \pm sem). Asterisks indicate $P<0.05$. 


\section{Discussion}

Early larval exposure to low dose teratogens alters egg-laying without improving embryo viability at later time points, which result in some overall detrimental impacts on fecundity and fertility. An improvement in embryonic viability at the latter time intervals was expected because adult hermaphrodites replenish their entire gonad every 6.5 hours (Hirsh et al., 1976), which implies that eggs laid during or after the 6-9 hour interval hours would have not been exposed to teratogens and egg-laying and egg quality should have increased at the latter two intervals compared to earlier intervals of 0-3 hours and 3-6 hours. While egg-laying improved during at the 9-12 hours interval, egg quality did not improve compared to either $0-3$ or 3-6 hours intervals, as measured by embryo viability. Due to specifics of gametogenesis in C. elegans, it is possible that teratogens may affect egg quality by altering sperm cell quality (Hirsh et al., 1976). It is also possible that chronic exposure to teratogens may be exacerbated by their extended bioactivity, or in some cases, through actions of their metabolites. These results indicate greater egg harvests are necessary to obtain an offspring population to further assess long-term teratogen effects on offspring.

This procedure using $C$. elegans not only identifies sub-lethal teratogen concentrations with potential long-term effects upon egg laying and quality, it provides the experimental platform to expand knowledge to prevent birth defects by developing interventions to ameliorate chronic subtoxic, teratogenic exposures upon the embryo, and is an initial step towards designing and testing safe therapeutics to be used before and during gestation. Developing phenotyping screens with simple organisms, such as C. elegans, is an efficient way to identify putative teratogens with potential long-term effects to further knowledge on the underlying developmental processes susceptible to environmental insults, and reveals the basis of how environment affects and shapes development.

\section{Data availability}

F1000Research: Dataset1. Dataset of screening sub-lethal teratogens on egg laying, hatching and viability in adult C. elegans during larval development, 10.5256/f1000research.8934.d124253 (Killeen \& Marín de Evsikova, 2016).

\section{Author contributions}

AK and CM conceived the study and designed the experiments. AK executed and analyzed the experiments. AK and CM drafted the manuscript. Both authors were involved in the revision of the draft and agreed to the final manuscript.

\section{Competing interests}

The authors have no competing interests to disclose.

\section{Grant information}

C. elegans $\mathrm{N} 2$ ancestral strain and E. coli $\mathrm{OP} 50$ strain was provided by the CGC, which is funded by NIH Office of Research Infrastructure Programs (P40 OD010440).

\section{Acknowledgements}

The authors thank Shpetim Karandrea for coding the groups to collect the data blind with respect to teratogen or control exposure.
Allard P, Colaiácovo MP: Bisphenol A impairs the double-strand break repair machinery in the germline and causes chromosome abnormalities. Proc Nat/ Acad Sci U S A. 2010; 107(47): 20405-20410.

PubMed Abstract | Publisher Full Text | Free Full Text

Hirsh D, Oppenheim D, Klass M: Development of the reproductive system of Caenorhabditis elegans. Dev Biol. 1976; 49(1): 200-219. PubMed Abstract | Publisher Full Text

Killeen A, Marín de Evsikova C: Dataset 1 in: Screening sub-lethal teratogens during larval development for long-term effects on egg laying, hatching, and viability in adult Caenorhabditis elegans. F1000Research. 2016.

Data Source

Parodi DA, Sjarif J, Chen Y, et al:: Reproductive toxicity and meiotic dysfunction following exposure to the pesticides Maneb, Diazinon and Fenarimol. Toxicol Res (Camb). 2015; 4(3): 645-654.

PubMed Abstract | Publisher Full Text | Free Full Text

Reed CE, Fenton SE: Exposure to Diethylstilbestrol during Sensitive Life

Stages: A legacy of Heritable Health Effects. Birth Defects Res C Embryo Today.
2013; 99(2): 134-146.

PubMed Abstract | Publisher Full Text | Free Full Text

Sanders AP, Desrosiers TA, Warren JL, et al: Association between arsenic, cadmium, manganese, and lead levels in private wells and birth defects prevalence in North Carolina: a semi-ecologic study. BMC Public Health. 2014; 14(14): 955.

PubMed Abstract | Publisher Full Text | Free Full Text

Stiernagle T: Maintenance of C.elegans. WormBook. ed. The C.elegans Research Community, WormBook, 2006; 1-11.

PubMed Abstract | Publisher Full Text | Free Full Text

Wigle DT, Arbuckle TE, Turner MC, et al:: Epidemiologic Evidence of Relationships Between Reproductive and Child Health Outcomes and Environmental Chemical Contaminants. J Toxicol Environ Health B Crit Rev. 2008; 11(5-6): 373-517.

PubMed Abstract | Publisher Full Text

Wilson JG: Environment and Birth Defects (Environmental Science Series). London: Academic Press; 1973. 


\section{Open Peer Review}

\section{Current Peer Review Status:}

\section{Version 1}

Reviewer Report 16 January 2017

https://doi.org/10.5256/f1000research.9613.r18823

(C) $\mathbf{2 0 1 7}$ Choe K. This is an open access peer review report distributed under the terms of the Creative Commons Attribution License, which permits unrestricted use, distribution, and reproduction in any medium, provided the original work is properly cited.

\section{Keith P. Choe}

Department of Biology, Genetics Institute, University of Florida, Gainesville, FL, USA

This is a study providing proof of principle for an approach to screening potential teratogens using the nematode model $C$. elegans. The small size, simple culturing methods, and genetic tractability of $\mathrm{C}$. elegans make it useful for rapid screening of compounds for biological activity and for identifying genetic factors that contribute to compound mode of action.

The results demonstrate the ability of the assay to detect compound effects on egg production and embryo viability. The authors might comment of embryo viability; the percent of eggs hatching is pretty low (generally under $50 \%$ even with vehicle control). Embryo viability on agar plates is usually far higher.

A useful modification of the assay would be to extend monitoring for the whole egg-laying period of 3-4 days to measure total eggs laid and to measure the latency of recovery on egg production and embryo viability.

Competing Interests: No competing interests were disclosed.

I confirm that I have read this submission and believe that I have an appropriate level of expertise to confirm that it is of an acceptable scientific standard.

Reviewer Report 06 January 2017

https://doi.org/10.5256/f1000research.9613.r19052

(C) 2017 Jones K. This is an open access peer review report distributed under the terms of the Creative Commons Attribution License, which permits unrestricted use, distribution, and reproduction in any medium, provided the original work is properly cited. 


\section{Keith T. Jones}

Centre for Biological Sciences, Faculty of Natural and Environmental Sciences, University of Southampton, Southampton, UK

This is a well conducted experiment examining the influence of various teratogens on the egg laying rate and embryo quality, and progeny, in C. elegans. There is an expected fall off in the fertility of worms exposed, however the actual rate of egg laying on initial exposure was raised.

My only comment would be that egg laying in worms is associated with/ needs worm movement. Thus you can get a 'bag of worms' phenotype if all movement is blocked. Hypothetically worm irritancy by noxious exposure in itself may promote movement, which then raises egg laying rate. It may be worthwhile commenting on this as a possibly explanation.

Competing Interests: No competing interests were disclosed.

I confirm that I have read this submission and believe that I have an appropriate level of expertise to confirm that it is of an acceptable scientific standard.

The benefits of publishing with F1000Research:

- Your article is published within days, with no editorial bias

- You can publish traditional articles, null/negative results, case reports, data notes and more

- The peer review process is transparent and collaborative

- Your article is indexed in PubMed after passing peer review

- Dedicated customer support at every stage

For pre-submission enquiries, contact research@f1000.com 